
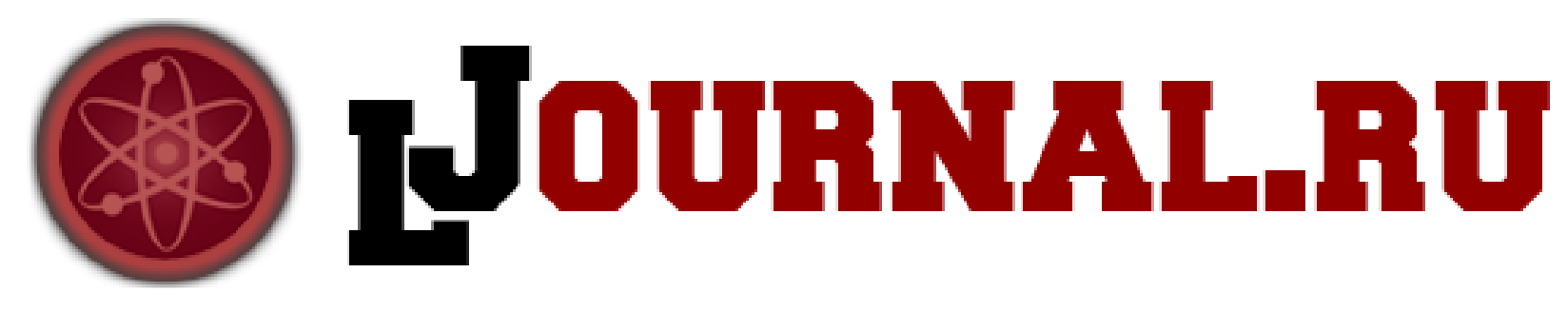

Чуприна Н.В.

Киевский национальный университет технологий и дизайна Украина, Киев

doi: 10.18411/1j2016-2-30

\title{
Разработка концепции создания проектного образа модного продукта в индустрии моды
}

Перед созданием художественного образа и разработкой эскизных предложений необходимо обстоятельно исследовать фактологический материал по избранной теме, композиционные и структурные основы построения объектапервоисточника, внешние условия его существования и принципы внутреннего развития. [1] Результаты такого анализа необходимо изложить в письменном виде, в логическом развитии и последовательной детализации фактов или аспектов темы.

Теоретическая часть концептуального описания обязательно дает небольшой обзор - исследование современных направлений в отрасли костюма, которые по своему характеру близки к создаваемому проектному образу.

Содержание концептуального описания обосновывается источником выбранной темы, с предоставлением его характеристик в пространстве, времени и художественной значимости. Авторская идея должна логично вытекать из источника и быть завершенной в образе.

Темой для разработки концепции проектного образа может быть любой объект, который имеет художественную ценность как исторических, так и современных событий или явлений. Рекомендуется избирать тему учитывая, что 
при разработке коллекции модного костюма необходима тщательная детализация концепции и обоснованная разработка ее структуры.

Концепция коллекции модного костюма, в которой отображена творческая разработка актуальной одежды, на основании избранного проектного источника, особенного массового спроса, должна включать такие последовательные этапы:

- вычленение из целостного образа каких-либо его свойств;

- объединение вычлененных свойств; усиление или ослабление свойств ассоциативного образа;

• перенесение этих свойств на объект проектной деятельности.

Создавая коллекцию на основе первоисточника, необходимо проектировать модели, в которых отображается современность, мода определенного периода. Создание новых интересных предложений неисчерпаемый источник, к которому должен обращаться дизайнер, чтобы его идеи и предложения не были оторванными от жизни, а наоборот, подчеркивали и дополняли ее.

Как и каждый новый проект в индустрии моды, разработка концепции и создание коллекции модной одежды должны нести определенный экспериментальный характер. Это необходимо, в первую очередь, в контексте полного действия и, даже, обязательности эксперимента в сам дизайне костюма. Важно то, что дизайнеры должны оперировать лишь профессиональным инновационным материалом, который уже прошел апробацию в практике дизайна. Это очевидно наиболее логический и эффективный путь не только пропаганды, но и совершенствования отдельных художественных средств и методов, которые и формируют общий процесс развития дизайна, в частности, художественного моделирования костюма.

Разработка концепции коллекции модной одежды, как правило, посвящена изучению средств прогнозирования развития форм костюма с учетом перспективных тенденций моды [2] В процессе разработки темы осуществляется поисковый анализ литературных истоков, каталогов, журналов моды, 
рекомендаций по формированию перспективного ассортимента актуальной модной одежды.

К этапам прогнозирования формы костюма как продукта индустрии моды включают такие:

- д динамика спроса и формирования рынка сбыта;

• определение типов потребителей;

- определение концепции ассортимента;

- определение концепции научно-технического развития производства;

- определение главных художественно-композиционных признаков (стилевое определение, ведущие силуэтные формы, колористика, структура и фактура материалов, рисунок на поверхности материала, декоративные элементы). [3]

При разработке концепции коллекции можно взять за основу любые признаки первоисточника, которые кажутся наиболее значимыми и наиболее отвечают требованиям современности и потребительского спроса. Однако, какие бы методы не использовались при создании модной формы костюма с определенным образным звучанием, главным остается одно - достичь гармоничной целостности и композиционной ясности конечного результата.

Важным фактором при создании модного костюма по мотивами разработанной концепции являются ассоциативные представления. Они позволяют достичь разнообразия рассматриваемого проектного образа и усилить новизну творческих решений. Ассоциация идей - это связь представлений, благодаря которым одно представление, которое зарождается в сознании, вызывает другое, связанное с первым по критериям подобия, сложности, смежности, противоположности или другими свойствами. Анализ базового фактического материала направлен на то, чтобы обнаружить как можно более разнообразные творческие подходы к стилизации объекта и определению его черт, которые целесообразно использовать при разработке коллекции модной одежды. 
Среди факторов, влияние которых необходимо отметить в ходе изучения темы-первоисточника, необходимо назвать такие: эстетический идеал эпохи, уровень развития искусства и моды, виды техники производства (текстиль, ткачество, методы изготовления), тип потребителя, влияние религиозных и бытовых условий, особенности климата и др. Кроме этого, если есть какие-то специфические факторы, которые влияют на формирование проектного образа, их также необходимо детально и последовательно описать при разработке концепции коллекции модного костюма.

Разработка концепции для создания коллекции модной одежды состоит из теоретической и графической частей, которые достаточно полно отображают избранную тему и создаваемый проектный образ костюма (пояснительная записка), а также графические разработки, отражающие модные тенденции сезона и принципы их адаптации к создаваемому проектному образу.

Содержание теоретической части концепции обосновывается источником избранной темы, с определением его художественной или практической ценности, а также анализом его характеристик в пространстве, времени и среде. Авторская идея должна логично выходить из источника и быть завершенной в образе.

Кроме того, в теоретической части подается аналитический обзор современных тенденций в отрасли дизайна костюма, которые по своему характеру близки к проектному образу создаваемой коллекции модной одежды.

При разработке капсул коллекции нужно применять главный проектный принцип - объединение в одной структуре явлений, которые характеризуют разные свойства костюма (пропорции, членение, колорит, декор и ин). Можно в то же время использовать и силуэт, и линию, и колористические или фактурные эффекты. Обобщенные формы могут соединяться с тщательно проработанными детальными изображениями. Такие контрастные сопоставления усиливают выразительность образов.

Определенную силу влияния имеет также нетрадиционность 
композиционного решения: преувеличения дают ощущение более острого образного влияния. Применяя ритмичное членение элементов композиционной структуры (вертикальное, горизонтальное, диагональное или другое) можно достичь выразительного влияния целостной композиции.

На вновь созданную основу трансформируется художественный образ первоисточника в виде тех или других методов адаптации модных тенденций: силуэт, многослойность, декоративность, сочетание тканей и материалов, принципы пропорциональности и внутреннего членения формы, средства композиции в том числе.

В разработке концепции принципы проектного развития образа могу быть разными:

- видоизменение геометрической формы;

- видоизменение колорита;

- видоизменение характера декора;

- видоизменение пропорциональности и членений;

- видоизменение целостного образа на одну его черту;

• любой другой принцип развития, обусловленный авторской концепцией.

Главное, чтобы целесообразность его использования была логично обоснована и чтобы применение этого принципа было отображено наглядно, понятно и последовательно.

Для этого необходимо найти эмоционально-выразительную форму объекта, отыскать такие пропорции, очертания, ритмы, цветовые отношения, материал, фактуру, орнамент, расположения, какие бы в совокупности отображали определенное эмоциональное состояние и настроение. При этом характерные мотивы первоисточников должны скорее восприниматься подсознательно и эмоционально, чем акцентироваться.

Эскизное предложение концепции рассчитано на создание взаимоувязанных капсул модной одежды (коллекции) на основе творческой трансформации одной нескольких наиболее образных и характерных свойств ли 
объекта-первоисточника, заданной темы или объекта исследования.

Кроме того, между всеми эскизами в коллекции должны сохраняться и те же закономерности логического и наглядного последовательного развития проектного образа и формы, что и в пределах каждого костюма-образа. Иначе говоря, каждое из эскизных предложений модного костюма должно воспроизводить разные, но взаимодополняющие черты объекта при создании его целостного образа.

В графической разработке концепции создания проектного образа модного продукта в индустрии моды необходимо использовать единую основу, в которую вкладывают обобщенную структуру модного костюма, общую для всех следующих форм, связанных между собой образной пластичной идеей.

На каждом этапе развития концепции одна и та же базовая форма и один и тот же образ может быть представлен несколькими вариантами, которые отличаются по объему и членениям, или по всем композиционным линиями. Этот фактор нужно иметь в виду при создании капсульной структуры коллекции модной одежды. Изменение объемов и силуэтных форм способствует разнообразию стилевых решений в процессе проектирования костюма.

Соответственно, при разработке концепции создания проектного образа нужно обнаружить принципы взаимосвязи характеристик модного костюма, основы сменяемости и развития формы: от малой к большой, от темной к светлой, от цельной лаконичной плотно члененной; от формы, композиционно расположенной наверху - к форме внизу композиции и пр. 
Chouprina N. V.

Kyiv National University of Technologies and Design

Development of conception of project appearance creation of fashion product in fashion industry

\begin{abstract}
In the article the criteria of development of design-conception of planning of suit on the basis of research of creative original source and fashion trends of planning season are considered. The structure of collection of fashion dress after certain creative and projects properties is described. Principles of assortments development are formulated. Principles of their transformation on the capsules of collection is certain. Principles of application colour, graphic and ornamental constituents of planning of modern suit in collection are analysed.
\end{abstract}

Keywords: fashion industry, fashion appearance, fashion trend, consumer demand, planning conception, suit collection

\title{
Литература:
}

1. Линч А. Изменения в моде: причины и следствия / А. Линч, М.Д. Штраус. Минск: Гревцов Паблишер, 2009. - 280 с.

2. Уайт Н. Fashion-бизнес: теория, практика, феномен / Н. Уайт, Й. Гриффитс. Минск: Гревцов Паблишер, 2008. - 272 с

3. Кавамура Ю. Теория и практика создания моды / Ю .Кавамура. - Минск: Гревцов Паблишер, 2009. - 192 с. 